\title{
Gelatin Endorses the Pluripotent Stem Cells from the Reprogrammed Fibroblasts of Adult Mice Differentiation into Subtypes of Neurons in the Feeder-Free Condition for a Long-Term
}

Gele Liu*

Department of Neuroscience, Carleton University, Canada

\begin{abstract}
Stem cell research and application in the basic and clinical fields have been leading a prevalent in the past 20 years since these present significantly promising meanings. The relevant technologies have momentously advanced, including the cellular matrix to offer stem cells growing healthily environment. Stem cells can originate from several resources such as embryonic and induced pluripotent stem cells (iPSCs) but they all are dependent on a monolayer of feeder-cells, which are, in the original and most time, on the primary mouse embryonic fibroblasts (MEF feeder cells) to sustain their self-renewal growing. However, even though MEF application is still widely applied in the research laboratory and commercial supplies, it meets inordinate challenging since it appears some noteworthy problems such as zoonosis, contaminations, and inconsistence outcomes. Importantly, the hindmost of those halts the downstream applications of stem cells, in particular, in the clinical application. Thus, scientists have hunted around the replacements either biomaterials or non-biomaterials and their mixtures. Recently, we magnificently employed the gelatin-alone-coated dishes in feeder-free condition with the opposite medium for the proliferation of iPSCs derived from the reprogrammed fibroblasts of the adult mouse to overcome these drawbacks of MEF. Moreover, such dishes sponsor the differentiation of iPSCs into succeeding neural progenitor cells, neurons, and as the ultimate product subtype of neurons - dopaminergic neurons up to 6 months. This system is simple, modest to accomplish with lower expenses
\end{abstract}

Keywords: Gelatin; Stem cells; Neurons; Feeder-free; Long-term

\section{Introduction}

Stem cell lines have been widely applied for the human developmental biology [1], drug discovery [2], and transplantation medicine [3,4] since the first report by Thomson in 1998 [5] with the derivation of human embryonic stem cells (hESCs) lines.

The embryonic and induced pluripotent stem cells (iPSCs) from various resources such as mouse or human should, in general, bank on a monolayer of feeder-cells such as the primary mouse embryonic fibroblasts (MEF feeder cells) to hold out the self-renewal of hPSCs. The primary derivation of hESCs lines was used by mitotically inactivated MEF feeder layer to grow hESC successively in an undifferentiated phase [5]. This protocol was thought the gold standard technique for hESCs culture. MEF cells achieve these important functions in stem cell culture: they secrete several vital growth factors such as fibroblast growth factors (FGFs), cytokines, and extracellular matrices (ECM) such as TGF $\beta$, activin A, laminin-511 and vitronectin into the medium [6-8], which support pluripotency and offer a cellular matrix for stem cells to grow. Fundamentally, feeder cells comprise in a layer of cells being incompetent to divide, which delivers extracellular secretions to promote the growth of target cells, which is dissimilar to a co-culture system because only one targeted-cell is proficient to proliferate. To avoid feeder cells to proliferate, they need to be treated by either one: the classical treatments as mitomycin or $\gamma$-irradiation, or the common conduct as electric pulses or chemical fixation [9].

However, several issues restrict MEF feeder cells to apply in the basic and clinical fields. For example, the result from the combined stem cells and feeder cells retort to various inducements and take a risk of zoonosis and contamination such as viruses or unknown proteins $[9,10]$. There are also existing the discrepancies in expression and secretion of these factors by different feeder- cells $[6,11]$ make it problematic to define which components are crucial for the provision of hPSCs in an undifferentiated state. Moreover, the treatments such as $\gamma$-irradiation for feeder-cells can induce apoptosis and afterward modifies the secretions, which may harmfully disturb the self-renewal hPSCs $[7,8]$.

Based on these matters above, recently, we established an effective protocol for the proliferation of iPSCs derived from the reprogrammed fibroblasts of the adult mouse by using the gelatin-alone-coated dishes with the appropriate Medium (see details in the MATERIALS AND METHODS). This model avoids the drawbacks of iPSCs culturing on feeder cell layers. Furthermore, the gelatin-coated dishes promote the differentiation of iPSCs into subsequent neural progenitor cells, neurons, and as the ending product subtype of neurons - dopaminergic neurons up to 6 months, which was relatively long-term.

\section{Materials and Methods}

\section{Coating plates, wells or slides}

As the regular coating for the primary cells cultures, a matrix of 100 x $60 \mathrm{~mm}$ plates, 6 -well plates or 4-chambered slides were respectively equipped with Poly-D-Lysine $\left(1 \mu \mathrm{g} / \mathrm{cm}^{2}\right.$ of surface area, Millipore A-003-E) and laminin (1 $\mu \mathrm{g} / \mathrm{cm}^{2}$ of surface area, Invitrogen 23017-015).

*Corresponding author: Gele Liu, Department of Neuroscience, 327 Life Sciences Research Building, Carleton University, 1125 Colonel By Drive, Ottawa, Ontario, Canada, Tel: +16135202600; E-mail: geleliu@gmail.com

Received March 12, 2018; Accepted March 21, 2018; Published March 31, 2018

Citation: Liu G (2018) Gelatin Endorses the Pluripotent Stem Cells from the Reprogrammed Fibroblasts of Adult Mice Differentiation into Subtypes of Neurons in the Feeder-Free Condition for a Long-Term. J Stem Cell Res Ther 8: 420. doi: 10.4172/2157-7633.1000420

Copyright: (c) 2018 Liu G. This is an open-access article distributed under the terms of the Creative Commons Attribution License, which permits unrestricted use, distribution, and reproduction in any medium, provided the original author and source are credited. 
Citation: Liu G (2018) Gelatin Endorses the Pluripotent Stem Cells from the Reprogrammed Fibroblasts of Adult Mice Differentiation into Subtypes of Neurons in the Feeder-Free Condition for a Long-Term. J Stem Cell Res Ther 8: 420. doi: 10.4172/2157-7633.1000420

Page 2 of 7

Specifically, Gelatin, as the sole attachment factor solution (Invitrogen S-006-100) at $0.1 \%$ concentration, was applied to coat all plates or wells in freshly daily use, in particular from iPSC stage to the subsequent multiple developing stages of neural cells, including the differentials to the neural progenitor cells, neural cells, mature neurons, and finally specific subtype of neurons - dopaminergic neurons. These procedures were kept a long-term period of 6 months.

\section{Culturing the primary cells}

The fibroblast cells from two-month-old adult CD1 mice were collected by micro-segmentation of tail-tips. The primary hippocampal cells of CD1 mouse were prepared from 2-month old adult animals. Tissues were composed with DMEM/F12 (Invitrogen 10565-018) and then were plated with $4 \mathrm{~mL}$ of DMEM/F12 for fibroblasts or of the Hibernate-E Medium without Ca2+ (BrainBits LLC, HE-Ca) for brain tissues. Following tissues chipped, small pieces were enzymatically consumed by papain (filter-sterilized $2 \mathrm{mg} / \mathrm{mL}$, Worthington, Cat. no. LS003119) for 45 minutes at $37^{\circ} \mathrm{C}$. After tissues being centrifugated, the cell-containing supernatant was re-suspended in $5 \mathrm{~mL}$ of Knockout DMEM (Invitrogen 10829-018) for fibroblast cells or of complete Hibernate $^{\oplus}$-E medium for brain cells. After centrifuged for 4 minutes at $200 \times \mathrm{g}$, supernatants were removed and then cell pellets were re-suspended in $41.5 \mathrm{~mL}$ DMEM/F-12 (Invitrogen10565-018) for fibroblast cells or $41.5 \mathrm{~mL}$ Neurobasal ${ }^{\circledR}$ medium (Invitrogen 21103 049) for brain cells. A 3-day used stock $50 \mathrm{~mL}$ of Neurobasal ${ }^{\circledR}$ medium or DMEM/F-12 was fabricated by mingling $50 \mu \mathrm{l}$ of $10 \mu \mathrm{g} / \mathrm{mL}$ (final $10 \mathrm{ng} / \mathrm{mL}$ ) of b-fibroblast growth factors (bFGF, Invtrogen 13256029), $7.5 \mathrm{~mL}$ of Knockout ${ }^{\text {Tm }}$ serum replacement (Invitrogen 10828028), $0.5 \mathrm{~mL}$ of MEM Non-Essential Amino Acids Solution (NEAA) (Invitrogen11140-050), $0.5 \mathrm{~mL}$ of L-glutamine (Invitrogen 25030-081), and $91 \mu \mathrm{l}$ (final $0.1 \mathrm{mM}$ ) of $\beta$ - mercaptoethanol (Invitrogen 21985-023). All cells were incubated at $37^{\circ} \mathrm{C}$ with $5 \% \mathrm{CO} 2$ humidified atmosphere and the fresh media were nourished every third day.

\section{Reprogramming factors inducing the formation of Induced Pluripotent Stem Cells (iPSCs)}

The non-viral vector with four reprogramming genes (c-Myc, Klf4, Oct4, and Sox2), labelled pCAG2LMKOSimO (Addgene, 20866), was exploited for reprogramming somatic fibroblasts into iPSCs [12]. This vector has the benefit creating virus-free, factor-removable iPSCs. These reprogramming genes are transcribing from the universally expressed synthetic CAG enhancer/promoter. The mOrange frame of the vector as a biomarker was in the same reading frame corresponding with these reprogramming transcription factors.

Cells with $85-90 \%$ confluence were transfected with the vector 20866 containing four reprogramming genes by using lipofectamine ${ }^{\oplus}$ 2000 (Invitrogen 11668-027). With the fresh proper media, cells were uninterruptedly cultured to sustain reprogramming hooked to pluripotency. The colonies of stem-cell-like with expressing the mOrange-positive marker were distinguished at Days 5-6 after transfection. The iPSCs were confirmed by means of the gene expressions of stem cell stage-specific antigens - Oct-4, SSEA-1, SSEA4, and GF141 (Millipore SCR002 and Millipore GF141). The iPSCs with the mOrange-positive marker were additionally recognized during Days 17-20. Then, these were relocated to the Neural Induction Medium in freshly coated-plates or wells comprising a $0.1 \%$ gelatin alone.

The transfection day was designated as Day 0. Through Days 1-14, the medium was newly altered with complete N2B27 Medium, containing with DMEM/F-12 (Invitrogen 11330-057) plus N-2
Supplement (Invitrogen 17502-048), B-27 Supplement (Invitrogen 17504-044), Knockout ${ }^{\text {tux }}$ serum replacement, L-glutamine, and NEAA, $\beta$-Mercaptoethanol. To promote the competence of the reprogramming, the medium was enhanced with a CHALP molecule cocktail

The CHALP cocktail is comprised with CHIR99021 (GSK3 $\beta$ inhibitor, $3 \mu \mathrm{M}$, Stemgent 04-0004), PD0325901 (MEK inhibitor, 0.5 $\mu \mathrm{M}$, Stemgent 04-0006), hLIF (human leukemia inhibitory factor, 10 ng/mL, Millipore LIF1005), A-83-01 (TGF- $\beta$ /Activin/Nodal receptor inhibitor, $0.5 \mu \mathrm{M}$, Stemgent, 04-0014), bFGF (100 ng/mL), and HA100 (ROCK inhibitor, $10 \mu \mathrm{M}$, Santa Cruz, sc-203072). The medium was provided with the Essential $8^{\mathrm{mi}}$ Medium (Prototype), confining DMEM/F-12 (HAM) 1:1, Essential $8^{\text {ma }}$ Supplement (50X) (Invtrogen A14666SA), N-2 Supplement, B-27 $7^{\circ}$ Supplement, Knockout ${ }^{\text {tix }}$ serum, L-glutamine, NEAA, and $\beta$-Mercaptoethanol from Day 15 to 20. All media were rehabilitated every three days.

\section{Differentiation of neural cells and succeeding dopaminergic neurons}

Neural progenitor cells were differentiated from the undifferentiated iPSCs by using a Neural Induction Medium from Days 21 to 28. This definite medium was produced with $50 \mathrm{~mL}$ Neurobasal ${ }^{\circ}$ medium plus bFGF, heparin solution (Sigma H3149, $50 \mu \mathrm{l}$ of $2-\mathrm{mg} / \mathrm{mL}$ ), N-2 supplement, glutaMAX ${ }^{\mathrm{mm}}-\mathrm{I}$ supplement, non-essential amino acids solution, Knockout ${ }^{\text {Tis }}$ serum replacement and $\beta$-Mercaptoethanol. During Days 29-35, a Dopaminergic Neuronal Progenitor Medium was applied to lead the neural progenitor cells for further differentiation into dopaminergic neural progenitors. This medium consisted of FGF-8b (100 ng/mL, Invitrogen PHG0271) and sonic hedgehog (200 ng/mL, SHH, R\&D systems 1314-SH-025), being liquefied into the Neurobasal ${ }^{\circ}$ medium with other nutrition contents - heparin solution, N-2 supplement without vitamin A (Invitrogen 12587-010), and NEAA. Lastly, the dopaminergic neural progenitor cells were supplementary differentiated into the matured dopaminergic neurons under using a Dopaminergic Neuronal Differentiation Medium from Days 36 to 50 . This medium contained the recombinant human BDNF ( $50 \mu \mathrm{l}$ of $25-\mu \mathrm{g} / \mathrm{mL}$, Invitrogen PHC7074), recombinant human GDNF $(50 \mu \mathrm{l}$ of $20-\mu \mathrm{g} / \mathrm{mL}$, Invitrogen PHC7045), ascorbic acid (50 $\mu \mathrm{l}$ of 200 $\mathrm{mM}$, Sigma A4403), dcAMP (Dibutyryl cyclic-AMP) (50 $\mu \mathrm{l}$ of 1-mM, Sigma D0627) in $50 \mathrm{ml}$ of the Neurobasal ${ }^{\circledR}$ medium accompanying with heparin, N-2 supplement without vitamin A (Invitrogen 12587-010) and NEAA. All media were freshened every three days.

\section{Immunocytochemistry}

To spot the introduction of reprogrammed stem cells, the biomarker mOrange (excitation and emission maxima are 549 and $565 \mathrm{~nm}$ by using the appropriate fluorescence filter), flagged to the 20866 vector that comprises the four re-programming genes.

Indicators of stem cell were distinguished by stem cell stagespecific antigens - Oct-4, SSEA-1, SSEA-4, and GF141. Undeveloped neuronal cells were perceived using anti-doublecortin (DCX) antisera (Invitrogen 48-1200), whereas mature neuronal cells were recognized by anti-MAP2 antibodies (Abcam ab32454), and to end, dopaminergic neuronal cells were evaluated using anti-tyrosine hydroxylase (TH) antisera (ImmunoStar 22941). All tests were performed according to the manufacturers' standardization protocols.

Cells biomarkers were harmoniously imagined with a Zeiss Axio Imager M2 microscope with Hamamatsu Orca $\mathrm{R}^{2}$ camera. Images were taken by applying Stereo Investigator and were adjusted for brightness/ 
Citation: Liu G (2018) Gelatin Endorses the Pluripotent Stem Cells from the Reprogrammed Fibroblasts of Adult Mice Differentiation into Subtypes of Neurons in the Feeder-Free Condition for a Long-Term. J Stem Cell Res Ther 8: 420. doi: 10.4172/2157-7633.1000420

contrast using ImageJ (National Institute of Health). Pictures were captured at $40 \mathrm{X}$ magnification where positive immunoreactivity.

\section{Results}

\section{Gelatin advocates reprogramming fibroblast to form iPSCs in the feeder-free circumstances}

The fibroblast cells of adult mice (Figure 1A) were composed from tail-tips for cell culturing. Cells were transfected with vector 20866 comprising four reprogramming genes and transformed into iPSCs from Days 17 to 20 . The positive colonies with biomarker mOrange (Figure 1B) of vector 20866 represented a stem-cell-like morphology at Days 5-6. The iPSCs were further confirmed by the expressions of stem cell stage-specific antigens: Oct-4 (Figure 1C), SSEA-1 (Figure 1D), SSEA-4 (Figure 1E), and GF141 (Figure 1F). Importantly, all colonies were thriven on gelatin-coated plates (gelatin is an attachment factor) with the feeder-free, suggesting successful reprogramming, and then selected during Days 17-20.

\section{Gelatin promotes the differential of iPSCs into subsequent and multiple staged neural cells}

Specifically, continuous using Gelatin, as an attachment factor, encourages the transformation of iPSCs into the distinctive various neural cells in the succeeding multiple footsteps. The iPSCs were initially transformed into neural progenitor cells with the network formation from Days 20-35 (Figure 2A-2I) and afterward (Days 36-50) the latter was guided to discriminate into mature neurons (Figure 2D), which were verified by Microtubule-associated protein 2 (MAP2) (Figure 2E). Then, the neurons were differentiated into dopaminergic phenotype (Figure 2G), being articulated the dopaminergic rate-limiting enzyme,
Tyrosine Hydroxylase (TH) (Figure 2H). The dopaminergic-like neurons have been continually monitored up to 6 months (183 days) under supporting of gelatin as the matric. These subsequent developing stages were scrutinized by the control groups of non-programmed tails in the parallel comparing in the same culturing conditions (Figure $2 \mathrm{C}$, 2F, and 2I).

\section{Gelatin sponsors the formation of neurons from embryonic brain cells as a control}

As the control experiments, to prove gelatin being capable as an appropriate matric coating material supporting the establishment of neurons from embryonic brain cells under the feeder-free surroundings, the hippocampal cells of the 2-month-old adult mouse were furnished for the primary culture. These neural cells were constantly tracked and monitored for the development. The cell living images of Days 25, 36, 40 and 183 were respectively documented (Figure 3A-3D). The results suggested that gelatin played the critical function to maintain the neuro cells up to 6 months at least.

\section{Discussion}

The first application of feeder cells in cell culture was described by Puck and Marcus in 1955. Despite the fact that some cell types are entirely hooked on the physical interaction with a feeder sheet for survival and expansion, several other feeder-dependent cells can be grown up on the feeder-free on condition. The latter is that cells are growing on the dishes coated with extracellular matrix proteins such as laminin, collagen, fibronectin, or Matrigel (extracellular matrix components) [9]. Recently, a simple and efficient protocol for the propagation of hPSCs using on a gelatin-coated dish in placenta-conditioned media has been developed [10]. However, we are still unclear whether or not iPSCs,
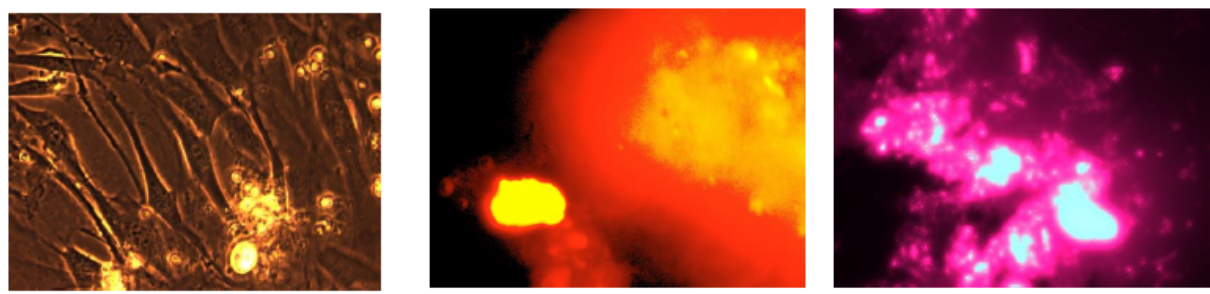

D. SSEA-1, iPSC colony

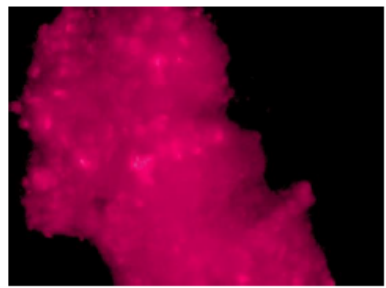

E. SSEA-4, iPSC colony

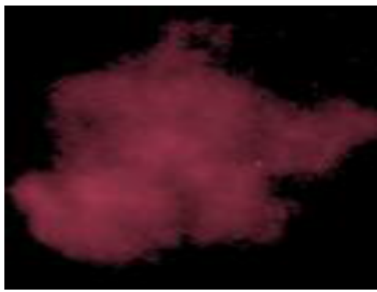

F. GF141, iPSC colony

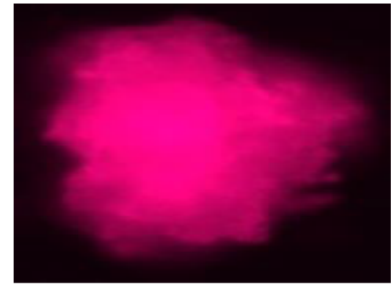

Figure 1: Gelatin-alone-coating plates support iPSCs derived from reprogrammed fibroblasts of the adult mouse in feeder-free surroundings. Gelatin, as the sole attachment factor (Invitrogen S-006-100) at $0.1 \%$ concentration, was practical to coat all plates on the base of the freshly daily use to replace the use of MEF seeds for the formation of iPSCs. The tail-tip fibroblast cells of adult CD1 mouse (A) were transfected using lipofectamine 2000 reagent with vector 20866 integrating the same proofreading frame with the four reprogramming transcription factors Oct4/Sox2/KIf4/c-Myc under culturing 17-20 days. Evidently, cells were altered into iPSCs as the biomarker expression of mOrange for vector 20866 (B) and the expressions of stem cell stagespecific antigens: Oct-4 (C), SSEA-1 (D), SSEA-4 (E), and GF141 (F). 
Citation: Liu G (2018) Gelatin Endorses the Pluripotent Stem Cells from the Reprogrammed Fibroblasts of Adult Mice Differentiation into Subtypes of Neurons in the Feeder-Free Condition for a Long-Term. J Stem Cell Res Ther 8: 420. doi: 10.4172/2157-7633.1000420

Days 25 A. Neural progenitor cells

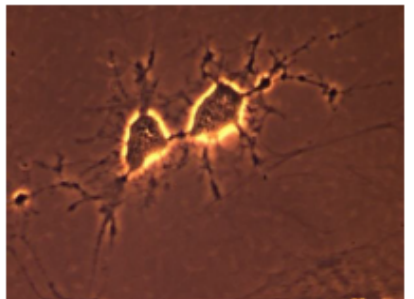

Day 36 D.

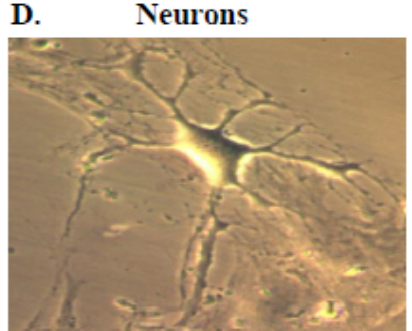

Day 183 G. Network of Neurons

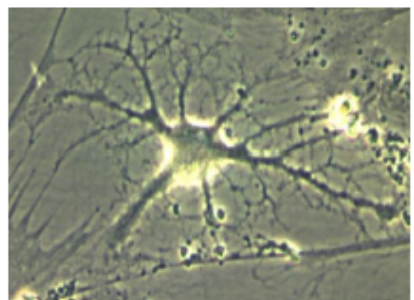

B. Network of Neural progenitor cells

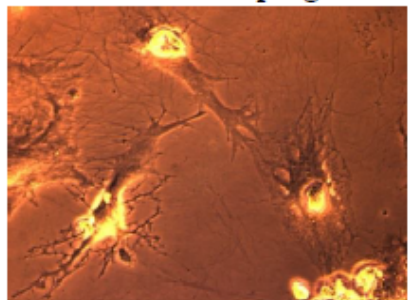

E.

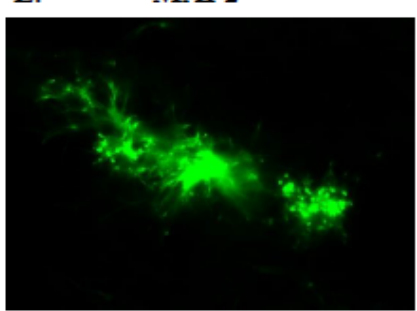

H.

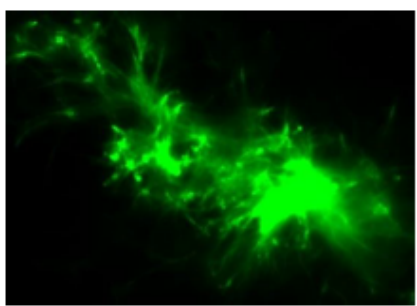

C. Non-reprogrammed tails

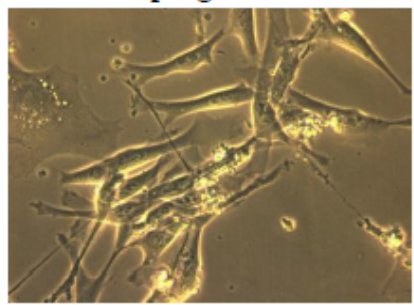

F. Non-reprogrammed tails

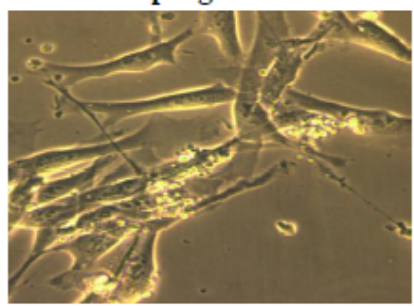

I. Non-reprogrammed tails

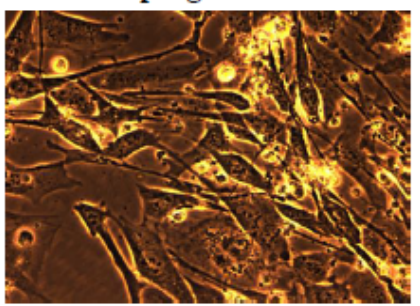

Figure 2: Gelatin endorses the iPSCs to differentiate into consequent several phased neural cells. As only one attachment factor, gelatin ( $0.1 \%$ concentration) was applied to coat all plates to withstand successive neural cells and neurons. The iPSCs were primarily transformed into the neural progenitor cells and their network formation ( $A$ and $B$ ) and subsequently led to mature neurons (D), which were validated by MAP2 (E). Finally, these neurons were discerned into subtype dopaminergic neurons $(G)$, evidenced by the dopaminergic rate-limiting enzyme, Tyrosine Hydroxylase $(T H)(H)$, indicating definitely these were mature neurons with the potential to produce dopamine. Prominently, the dopaminergic neurons were constantly living healthily up to 6 months (183 days) with gelatin as single supporting matric. All these were parallelly examined by non-programmed tails as the internal control groups, suggesting that these cells were maintained the same cell morphology (C, F, and I).

derived from the reprogrammed fibroblasts of the adult mouse, on an alternative option gelatin-alone-coated dish with other conventional resource media such as DMEM/F-12 (see details in the MATERIALS AND METHODS), are growing healthily; and whether or not such gelatin-coated dishes are able to encourage the differentiation of iPSCs into subsequent subtypes of neurons in the relatively long-term.

With the prodigious interests in the past 20 years, scientists have been looking for the substitute options for the MEF feeder layer in order to avoid its drawbacks, as described in the Introduction section. However, there are still some issues to be addressed at present. For example, the exposures of hESC to xenopathogens are immense risks since the human feeder layers such as fetal muscle, fetal skin, foreskin fibroblasts, and adult fallopian tubal epithelial feeder cells, amniotic mesenchymal cells, have been applied [13-17]. Although these some studies to avoid the ethical problems, an additional blockade still exists with immunological incompatibility causing tissue rejection and requiring the use of immune-suppressing agents [18]. Fortunately, the advanced technology eliminates the ethical concerns and immunological issues by using iPSCs from autologous patient-specific stem cells, which is reprogrammed and induced by transcription factors, modified mRNA, chemical agents, direct protein introduction, or gene transfer [19-21]. However, unfortunately, now many laboratory and commercial biotechnological companies are still maintaining hiPSCs on animal-derived feeder cells such as MEF since it has the significant security of the nutrition to supply hiPSCs growing with glowing. Thus, the replacement of allogeneic or xenogeneic feeder layers is still challenging for the downstream clinical application [22]. The extracellular matrix (ECM) proteins, such as laminin [23], vitronectin [24], collagen [25,26], fibronectin [10,27], or their mixed products such as Matrigel $[9,28]$, with the synthetic polymer surfaces [29-33] support undifferentiated hPSCs proliferation in the feeder-dependent or feeder-free cultures. As one of the most commonly used substrates, Matrigel plays an important starting point to outline the prerequisites for hPSCs growth and differentiation. However, Matrigel derived from Engelbreth-Holm-Swarm mouse sarcomas [34] may display lotto-lot inconsistency and may introduce xenogeneic impurities. Thus, Matrigel is not a supreme substrate for the feeder-free culture of hPSCs for ultimate human therapy. The recombinant human (rh) laminin-511 [35], rh vitronectin [36], and rh E-cadherin [37] were considered as the noteworthy landmarks when at the first time they were applied in the culture of hPSCs as the xenogeneic-free substrates. In addition, the recombinant protein fragments recombinant fibronectin fragment (FN III) and FBNI fragment (PF8) supported the human embryonic stem cell chondrogenesis [38]. Furthermore, the mixtures of fibronectin, 
A.

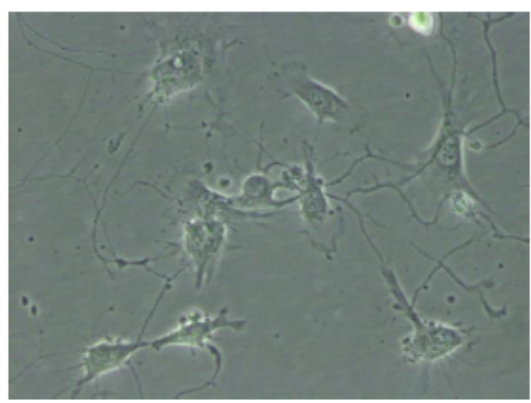

C.

Day 40

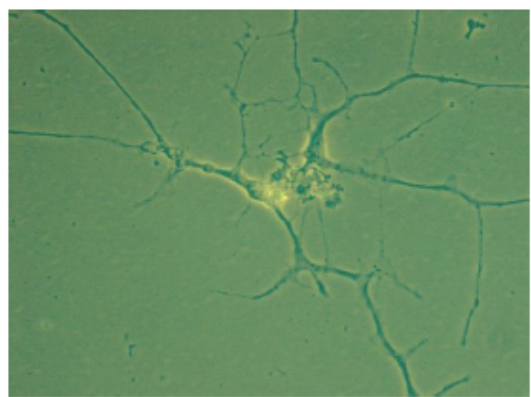

B.

Day 36

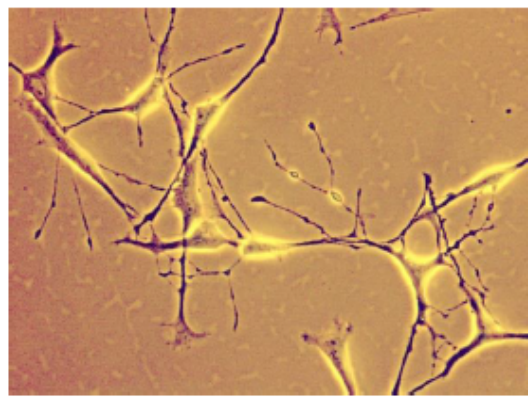

D.

Day 183

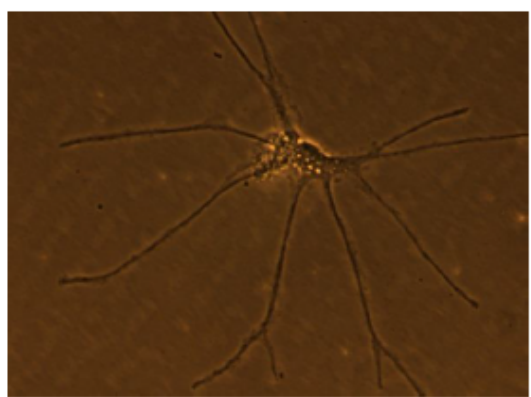

Figure 3: Gelatin is a guarantor for the development of neurons from embryonic brain cells as the external control. Gelatin, as the single attachment factor to coat the plates at $0.1 \%$ concentration, supports culturing embryonic brain cells during a 6 -month period. As the external control, hippocampal cells of the 2 -month-old adult mouse were sustained by gelatin-alone-coating plates. The images of cells on Days 25, 36, 40 and 183 were correspondingly shot (A-D).

laminin, and gelatin have been added into the suspension settings of the culture medium [39].

Based on these subjects above, we wonder whether or not gelatin, as the sole biomaterial to coat dishes or wells, is proficient to use in the feed-free culturing milieu for iPSCs derived from the reprogrammed fibroblasts of the adult mouse. Gelatin is a mixture of peptides and proteins formed by hydrolysis of collagen extracted from the skin, bones, and connective tissues. The promotive effect of gelatin-based hydrogels on chondrogenic differentiation of mesenchymal stem cells in vitro has been found [40]. The gelatin-coating of porous poly( $\varepsilon$ caprolactone) scaffolds supported growth and osteogenesis of human mesenchymal stem cells (hMSCs) in vitro [41]. Furthermore, according to our results, the gelatin-alone-coating cell culture plates are efficacy for iPSCs reprogramming and living on the feed-free setting with the appropriate mediums to replace the MEF environment with evading its downsides, described the above (Figure 1). Moreover, it's surprising to us that such coating plates can uphold the subsequent neural progenitor cells, neural cells, and dopaminergic neurons in feeder-free conditions in the relative long-term up to 6 months (Figure 2). This function of such plates has been validated by the control group - embryotic brain cells were well-growing on the same condition up to the same period (Figure 3). Gelatin-alone- application is an alternative to others such as laminin, collagen, fibronectin, or their mixtures Matrigel. In addition, this method facilitates simple to handle and decreases the costs.

In the meaning time, we need to point out that the most critical role which the gelatin-alone-coating plates/wells play is the physical contact and support iPSCs and subtypes of neurons but not secrete the growth factors and ECM, as MEF does. Thus, the suitable medium must be used with it together in order to provide enough nutrients to these cells. Therefore, the nourishing components have been added to the proper mediums, respectively, up to different stages (see details in the MATERIALS AND METHODS). The feeder layers such as MEF sustain the growth of target cells by releasing growth factors such as FGFs, as a critical nutritious factor to the culture media, and as the attachment factor to support and to detoxify the culture medium or synthesizing extracellular matrix proteins [15,42]. FGFs are compelling controllers of cell proliferation, differentiation, and function and are critically domineering in normal development, tissue maintenance and wound restoration [10]. Thus, the gelatin-coating for the physical contacting and supporting function, along with other growth factors (as the standardization uses) such as b-fibroblast growth factors (bFGF) [11,43-45], to replace the MEF were employed during our experiments. Another one leukemia inhibitory factor (LIF), a cytokine required for maintaining both the proliferation and developmental potential of stem cells, was also applied as a conventional factor [46]. In addition, HA100 (ROCK inhibitor) was used as survival signals, including inhibition of apoptosis and cell detachment, mediated by remodeling of the actin cytoskeleton as well [47-49].

In summary, in order to optimize the applications of stem cell, in particular, iPSCs, in the human developmental biology, drug, and transplantation medicine, one of the most important techniques is how to overcome the disadvantages of the MEF feeder cells such as zoonosis, contaminations, and inconsistency results, etc. The gelatin-alone- 
Citation: Liu G (2018) Gelatin Endorses the Pluripotent Stem Cells from the Reprogrammed Fibroblasts of Adult Mice Differentiation into Subtypes of Neurons in the Feeder-Free Condition for a Long-Term. J Stem Cell Res Ther 8: 420. doi: 10.4172/2157-7633.1000420

Page 6 of 7

coating cell culture plates have been studied. We have found that such plates/wells with the suitable culturing mediums are the efficiencies for iPSCs derived from the reprogrammed fibroblasts of adult mice and they are differential into subtypes of neurons in the feeder-free condition for the relative long-term up to 6 months. Managing this system is humble with lower costs.

\section{Acknowledgments}

This work was supported by grants from the Canadian Institutes of Health Research.

\section{Disclosure of Potential Conflicts of Interest}

The author declares no conflict of interest.

\section{References}

1. Wobus AM, Boheler KR (2005) Embryonic stem cells: prospects for developmental biology and cell therapy. Physiol Rev 85: 635-78. [PubMed]

2. Avior Y, Sagi I, Benvenisty N (2016) Pluripotent stem cells in disease modelling and drug discovery. Nat Rev Mol Cell Biol 17: 170-82. [PubMed]

3. Hodges H, Pollock K, Stroemer P, Patel S, Stevanato L (2007) Making stem cell lines suitable for transplantation. Cell Transplant 16: 101-15. [PubMed]

4. DeFrancesco L (2012) Adult stem cell therapies walk the line. Nat Biotechnol 30: 739-41. [PubMed]

5. Thomson JA, Itskovitz-Eldor J, Shapiro SS, Waknitz MA, Swiergiel JJ (1998) Embryonic stem cell lines derived from human blastocysts. Science 282: 11451147. [PubMed]

6. Hongisto H, Vuoristo S, Mikhailova A, Suuronen R, Virtanen I (2012) Laminin-511 expression is associated with the functionality of feeder cells in human embryonic stem cell culture. Stem Cell Res 8: 97-108. [PubMed]

7. Villa-Diaz LG, Nandivada H, Ding J, Nogueira-de-Souza NC, Krebsbach PH (2010) Synthetic polymer coatings for long-term growth of human embryonic stem cells. Nat Biotechnol 28: 581-583. [PubMed]

8. Villa-Diaz LG, Pacut C, Slawny NA, Ding J, O'Shea KS (2009) Analysis of the factors that limit the ability of feeder cells to maintain the undifferentiated state of human embryonic stem cells. Stem Cells Dev. 18: 641-651.

9. Sara Llames, Eva García-Pérez, Álvaro Meana, Fernando Larcher, Marcela de Río (2015) Feeder Layer Cell Actions and Applications. Tissue Eng Part B Rev 21: 345-353. [PubMed]

10. Jung JH, Kim BS (2015) A Novel Culture Model for Human Pluripotent Stem Cell Propagation on Gelatin in Placenta-conditioned Media. J Vis Exp 3: e53204.

11. Eiselleova L, Peterkova I, Neradil J, Slaninova I, Hampl A (2008) Comparative study of mouse and human feeder cells for human embryonic stem cells. Int $\mathrm{J}$ Dev Biol. 52: 353-363. [PubMed]

12. Kaji, K, Norrby, K, Paca, A, Mileikovsky, M, Mohseni, P, andWoltjen, K (2009) Virus-free induction of pluripotency and subsequent excision of reprogramming factors. Nature 458: 771-775

13. Yu J, Chau KF, Vodyanik MA, Jiang J, Jiang Y (2011) Efficient Feeder-Free Episomal Reprogramming with Small Molecules. PLoS One 6: e17557. [PubMed]

14. Puck T.T., and Marcus P.I. (1955) A rapid method for viable cell titration and clone production with HeLa cells in tissue culture: the use of $x$-irradiated cells to supply conditioning factors. Proc Natl Acad Sci USA 41: 432. [PubMed]

15. Richards M, Fong CY, Chan WK, Wong PC, Bongso A (2002) Human feeders support prolonged undifferentiated growth of human inner cell masses and embryonic stem cells. Nat Biotechnol 20: 933. [PubMed]

16. Amit M, Margulets V, Segev H, Shariki K, Laevsky IR (2003) Human feeder layers for human embryonic stem cells. Biol Reprod 68: 2150. [PubMed]

17. Zhang K, Cai Z, Li Y, Shu J, Pan L (2011) Utilization of human amniotic mesenchymal cells as feeder layers to sustain propagation of human embryonic stem cells in the undifferentiated state. Cell Reprogram 13: 281.
18. Pan C, Hicks A, Guan X, Chen H, Bishop CE (2010) SNL fibroblast feeder layers support derivation and maintenance of human induced pluripotent stem cells. J Genet Genomics 37: 241. [PubMed]

19. Takahashi K, Yamanaka S (2006) Induction of pluripotent stem cells from mouse embryonic and adult fibroblast cultures by defined factors. Cell 126 663-676.

20. Nishimura K, Takahashi J (2013) Therapeutic application of stem cell technology toward the treatment of Parkinson's disease. Biol Pharm Bull 36 171-175. [PubMed]

21. Anchan RM, Quaas P, Gerami-Naini B, Bartake H, Griffin A (2011) Amniocytes can serve a dual function as a source of iPS cells and feeder layers. Hum Mo Genet 20: 962

22. Nishishita N, Shikamura M, Takenaka C, Takada N, Fusaki N (2012) Generation of virus-free induced pluripotent stem cell clones on a synthetic matrix via a single cell subcloning in the naïve state. PLoS One 7: e38389. [PubMed]

23. Li Y, Powell S, Brunette E, Lebkowski J, Mandalam R (2005) Expansion of human embryonic stem cells in defined serum-free medium devoid of animalderived products. Biotechnol Bioeng. 91: 688-698.

24. Chen G, Gulbranson DR, Hou Z, Bolin JM, Ruotti V (2011) Chemically defined conditions for human iPSC derivation and culture. Nat Methods. 8: 424-429. [PubMed]

25. Yongxing Liu, Jon G, James ED, Gloria AG (2012) One-Step Derivation of Mesenchymal Stem Cell (MSC)-Like Cells from Human Pluripotent Stem Cells on a Fibrillar Collagen Coating. PLoS One. 7: e33225. [PubMed]

26. Mitra L, Aiping L, Seth DT, Paul DR (2013) Isolation of Muscle-Derived Stem/ Progenitor Cells based on adhesion characteristics to collagencoated surfaces. Methods Mol Biol 976: 53-65. [PubMed]

27. Lu J, Hou R, Booth CJ, Yang SH, Snyder M (2006) Defined culture conditions of human embryonic stem cells. Proc Natl Acad Sci USA. 103: 5688-5693. [PubMed]

28. Xu C, Inokuma MS, Denham J, Golds K, Kundu P, Gold JD, Carpenter MK (2001) Feeder-free growth of undifferentiated human embryonic stem cells. Nat Biotechnol 19: 971

29. Chang CW, Fernandez A, Willert K, Varghese S, Chien S (2010) Long-term human pluripotent stem cell self-renewal on synthetic polymer surfaces. Biomaterials 31: 9135-9144.[PubMed]

30. Klim JR, Li L, Wrighton PJ, Piekarczyk MS, Kiessling LL (2010) A defined glycosaminoglycan-binding substratum for human pluripotent stem cells. Nat Methods 7: 989-994.

31. Mei Y, Saha K, Bogatyrev SR, Yang J, Hook AL (2010) Combinatoria development of biomaterials for clonal growth of human pluripotent stem cells. Nat Mater 9: 768-778. [PubMed]

32. Melkoumian Z, Weber JL, Weber DM, Fadeev AG, Zhou Y (2010) Synthetic peptide-acrylate surfaces for long-term self-renewal and cardiomyocyte differentiation of human embryonic stem cells. Nat Biotechnol 28: 606- 610 . [PubMed]

33. Irwin EF, Gupta R, Dashti DC, Healy KE (2011) Engineered polymer-media interfaces for the long-term self-renewal of human embryonic stem cells. Biomaterials 32: 6912-6919. [PubMed]

34. Kleinman HK, McGarvey ML, Liotta LA, Robey PG, Tryggvason K (1982) Isolation and characterization of type IV procollagen, laminin, and heparan sulfate proteoglycan from the EHS sarcoma. Biochemistry 21: 6188-6193.

35. Miyazaki T, Futaki S, Hasegawa K, Kawasaki M, Sanzen N (2008) Recombinant human laminin isoforms can support the undifferentiated growth of human embryonic stem cells. Biochem Biophys Res Commun 375: 27-32. [PubMed]

36. Braam SR, Zeinstra L, Litjens S, Ward-van Oostwaard D, van den Brink S (2008) Recombinant vitronectin is a functionally defined substrate that supports human embryonic stem cell self-renewal via alphavbeta5 integrin. Stem Cells 26: 2257-2265. [PubMed]

37. Nagaoka M, Si-Tayeb K, Akaike T, Duncan SA (2010) Culture of human pluripotent stem cells using completely defined conditions on a recombinant E-cadherin substratum. BMC Dev Biol 10: 60. [PubMed]

38. Cheng A, Cain SA, Tian P, Baldwin AK, Uppanan P (2018) Recombinant Extracellular Matrix Protein Fragments Support Human Embryonic Stem Cell Chondrogenesis. Tissue Eng 10: 60. 
Citation: Liu G (2018) Gelatin Endorses the Pluripotent Stem Cells from the Reprogrammed Fibroblasts of Adult Mice Differentiation into Subtypes of Neurons in the Feeder-Free Condition for a Long-Term. J Stem Cell Res Ther 8: 420. doi: 10.4172/2157-7633.1000420

39. Steiner D, Khaner H, Cohen M, Even-Ram S, Gil Y, Itsykson P (2010) Derivation, propagation and controlled differentiation of human embryonic stem cells in suspension. Nat Biotechnol 28: 361-364. [PubMed]

40. Salamon A, van Vlierberghe S, van Nieuwenhove I, Baudisch F, Graulus GJ (2014) Gelatin-Based Hydrogels Promote Chondrogenic Differentiation of Human Adipose Tissue-Derived Mesenchymal Stem Cells In Vitro Materials (Basel) 7: 1342-1359. [PubMed]

41. Zhang Q, Tan K, Zhang Y, Ye Z, Tan WS (2014) In situ controlled release of rhBMP-2 in gelatin-coated 3D porous poly( $\varepsilon$-caprolactone) scaffolds for homogeneous bone tissue formation. Biomacromolecules 15: 84-94. [PubMed]

42. Namba M, Fukushima F, Kimoto T (1982) Effects of feeder layers made of human, mouse, hamster, and rat cells on the cloning efficiency of transformed human cells. In Vitro 18: 469. [PubMed]

43. Vallier L, Alexander M, Pedersen RA (2005) Activin/Nodal and FGF pathways cooperate to maintain pluripotency of human embryonic stem cells. J Cell Sci 118: 4495.

44. Kueh J, Richards M, Ng SW, Chan WK, Bongso A (2006) The search for factors in human feeders that support the derivation and propagation of human embryonic stem cells: preliminary studies using transcriptome profiling by serial analysis of gene expression. Fertil Steril 85: 1843. [PubMed]

45. Greber B, Lehrach H, Adjaye J (2007) Fibroblast growth factor 2 modulates transforming growth factor beta signaling in mouse embryonic fibroblasts and human ESCs (hESCs) to support hESC self-renewal. Stem Cells 25: 455

46. Fleischmann G, Müller T, Blasczyk R, Sasaki E, Horn PA (2009) Growth characteristics of the nonhuman primate embryonic stem cell line cjes001 depending on feeder cell treatment. Cloning Stem Cells 11: 225.[PubMed]

47. Nanba D, Matsushita N, Toki F, Higashiyama S (2013) Efficient expansión of human keratinocyte stem/progenitor cells carrying a transgene with lentiviral vector. Stem Cell Res Ther 4: 127.

48. Palechor-Ceron N, Suprynowicz F, Upadhyay G, Dakic A, Minas T (2013) Radiation induces diffusible feeder cell factor(s) that cooperate with ROCK inhibitor to conditionally reprogram and immortalize epithelial cells. Am J Patho 183: 1862. [PubMed]

49. Zhou Q, Duan H, Wang Y, Qu M, Yang L (2013) ROCK inhibitor Y-27632 increases the cloning efficiency of limbal stem/progenitor cells by improving their adherence and ROS-scavenging capacity. Tissue Eng Part C Methods 19: 531. [PubMed] 